\title{
Introduction to a Book Forum on Pastoral Aesthetics: A Theological Perspective on Principlist Bioethics by Nathan
} Carlin

\author{
Claire D. Clark ${ }^{1}$
}

Accepted: 27 September 2021 / Published online: 12 October 2021

(C) The Author(s), under exclusive licence to Springer Science+Business Media, LLC, part of Springer Nature 2021

\begin{abstract}
The author offers an introduction to the essays in a book forum on Carlin in Pastoral Aesthetics: A Theological Perspective on Principlist Bioethics (2019).

Keywords Bioethics · Pastoral theology $\cdot$ History of medicine $\cdot$ Clinical pastoral education $\cdot$ Chaplaincy $\cdot$ Medical humanities $\cdot$ Clinical ethics $\cdot$ Method of correlation $\cdot$ Art theory
\end{abstract}

"Beginning in the 1960s," wrote historian Rothman (1991), "the practice of medicine in the United States underwent a most remarkable — and thoroughly controversial-transformation" (p. 1). In the introduction to Strangers at the Bedside: A History of How Law and Bioethics Transformed Medical Decision Making, Rothman painted a picture of this bioethics revolution. The image of the physician alone with a patient was displaced by a new and different scene: an examining room so crowded with bystanders that the doctor could barely enter it. Each of the strangers at the bedside was also an expert - a lawyer, a judge, a legislator, or an ethics committee member-ready to mediate medical decisions that had once belonged only to the physician. At the forefront of the crowd were "the bioethicists, who stood ready to replace bedside ethics with armchair ethics, to draw on philosophers' first principles, not on the accumulated experience of medical practice" (Rothman, 1991, p. 2).

The four principles that the bioethicists would use to guide medical decision-makingrespect for autonomy, beneficence, nonmaleficence, and justice-were articulated by philosophers Tom Beauchamp and James Childress in response to a series of bioethical crises beginning in the 1960s. As patients gained primacy, events such as the legalization of abortion, the invention of the artificial heart, the first successful organ transplant, and the newfound technical ability to pronounce an unconscious patient "brain dead" contributed to the collapse of the moral paradigm founded on physician paternalism. Beauchamp and Childress's Principles of Biomedical Ethics, originally published in (1979), defined the terms that would help identify these kinds of emerging bioethical dilemmas as well as

Claire D. Clark

claire.clark@uky.edu

1 Department of Behavioral Science, University of Kentucky, 1100 Veterans Drive, Lexington, KY 40536-0086, USA 
reconcile them. Respect for autonomy meant honoring patient's rights to make their own fully informed medical decisions. Nonmaleficence meant physicians were obligated to avoid harm; beneficence meant they should also act in ways that promoted patients' wellbeing. Justice, though harder to define, often meant that the risks and benefits of medical research should be evenly distributed across the population and that patients ought to have equal opportunity to access effective health care.

Introducing these four ethics principles into clinical decision-making amounted to a revolutionary shift in medical practice. Physicians had once made life-or-death decisions for patients based solely on professional instinct, divine inspiration, and even personal prejudice; they would now be required to take these four principles into account, weighing, balancing, and specifying them in order to come to a decision. Principlist bioethics became institutionalized through standardized questions on high-stakes exams, in deliberations in hospital and research ethics committee meetings, and in the new field of clinical ethics, which generated its own specialist literature.

The specialist literature met with dissent. Critics argued that Beauchamp and Childress's system prioritized respect for autonomy above the other three principles and reflected a moral philosophy that was Eurocentric and masculine rather than universally applicable. Yet the most enduring criticism of principlist bioethics was an attitude, not an argument. As bioethics became an increasingly bureaucratic exercise, philosophers risked becoming functionaries who applied the four principles in a rote and unreflective manner. Carlin (2019), an ordained minister and medical school professor, diagnoses the central problem with the system: "[P] rinciplist bioethics pays insufficient attention to experience and to context" (p. 15).

In what I take to be a groundbreaking book-Pastoral Aesthetics: A Theological Perspective on Principlist Bioethics - Carlin "criticizes the critics" of Principles of Biomedical Ethics by viewing the four principles from the perspective of pastoral theology. Pastoral theology connects interpretations of sacred scripture to lived experience; Carlin argues that pastoral theologians are thus uniquely equipped to enrich our understanding of both the experiences and contexts of principlist bioethics.

I would like to point out that Carlin's approach represents a departure from other work on religion and bioethics, which tends to apply specific materials or perspectives from various religious traditions to contemporary bioethical issues. In contrast, Carlin argues that because, in his view, pastoral theology is grounded in a sensibility rather than a particular religious content, it can inspire clinicians and ethicists to consider the psychological, existential, and spiritual dimensions of medical practice.

And it can do so without alienating them from each other. Carlin lists Rothman's Strangers at the Bedside in his comprehensive bibliography, and it seems reasonable to assume that Rothman's history represents the sort of bioethics origin story that Pastoral Aesthetics seeks to enrich. In Dykstra's (2005) edited collection Images of Pastoral Care, the figures at the bedside are imagined as caregivers, privileged listeners who had access to the patients' experiences decades before the introduction of professional clinical ethicists; to consider Dysktra and Rothman together, Dysktra's (1990) own image of pastoral theology is that of the "intimate stranger." Unlike Rothman's impartial bureaucrat at the bedside, Dykstra's curious chaplain brings the wisdom of their own personal experiences to the clinical crisis, engendering empathy and sympathy and consciously evoking intense emotion. For students of the history of bioethics, Carlin's decision to foreground pastoral theology is an interpretive choice as well as an aesthetic one.

Carlin was mentored by Dykstra, and he writes that he is less interested in advancing his own singular vision of pastoral care than in exploring how others' images of pastoral theology 
can encourage fresh ways of seeing principlist bioethics. According to Dysktra, pastoral theology's diverse alternatives to Rothman's stranger at the bedside-figures such as the indigenous storyteller, the wounded healer, the courageous shepherd, the self-differentiated Samaritan, the midwife, and the gardener-share several important characteristics. They work at the margins of medicine and bioethics and identify with the marginalized. They work with individual patients' psychology. They view religious truth as personal rather than universal. Their perspective is inclusive of different religious orientations and particular to each patient's point of view. For both Dykstra and Carlin, pastoral theology offers the kinds of truths that are best understood through analogy and accessed through art. Carlin (2019) writes:

By envisioning pastoral theology as aesthetic imagination, Dykstra emphasizes that he is not offering a how-to manual with regard to the practice of pastoral care but rather a sensibility of and for pastoral theology, a sensibility that is akin to critical art appreciation. This book does the same for bioethics, for it, too, is not a how-to manual. It offers a way of looking at things. (pp. 31-32)

Pastoral Aesthetics' approach is inspired by theologian Paul Tillich's method of correlating theology with culture. In Carlin's method of correlation, images of pastoral care (theology) are put in conversation with each of the bioethical principles (culture) in order to "uncover new-and sometimes mundane-issues for moral consideration" (p. 26). In each chapter of the book, Carlin introduces and illustrates a bioethical principle, discusses an analogous image of pastoral care, and ultimately generates new meaning through an original correlation of the principle and the image.

In this way, respect for autonomy is illustrated with the end-of-life-case of Karen Ann Quinlan, correlated with the image of the living human document, and explored through a psychoanalytic interpretation of the book A Monster Calls (Ness, 2013). Nonmaleficence is illustrated with the case of Alice Roe's abortion, correlated with the image of the circus clown, and explored through an analysis of the use of humor in two seemingly disparate sources, The Diving Bell and the Butterfly (Bauby, 1998) and Cancer is Funny: Keeping Faith in Stage-Serious Chemo (Micheli, 2016). Beneficence is illustrated with the case of the first heart transplant, correlated with the image of the diagnostician, and explored through a reflection on the life and writing of one of the students in Carlin's Pathologies of Mental Illness class. Finally, the principle of justice is illustrated with the story of the "God Squad," a Seattle committee formed to make the first decisions about who should receive kidney transplants, along with the racist architecture of the Tuskegee Syphilis Study, correlated with the image of the living human web, and explored through the unjust death of Emmett Everett as recounted in Five Days at Memorial: Life and Death in a Storm-Ravaged Hospital by Fink (2013).

Carlin's critical analysis is contemplative in tone. He invites the reader into his references and articulates the connections between his associations; as a result, each chapter feels more like a long talk with a trusted and well-read friend than a prescriptive sermon. I should acknowledge here that my perspective might influence this reading. I met Nate Carlin during my fellowship at the McGovern Center for Humanities and Ethics around the time his third book, Religious Mourning (2014), had been published. I was then finishing an interdisciplinary doctoral program supervised by a dissertation committee that included my advisor Howard Kushner, a historian of medicine and public health; David Courtwright, a historian of alcohol and drugs; Matthew Bernstein, a historian of film and media; and Gary Laderman, a historian of American religious cultures. While I had done some reading in the histories of psychology and religion, I had a lot to learn about bioethics and had never heard of pastoral theology. My introduction to 
Carlin thus helped shape my understanding of how pastoral theology could sound, and through his writing I gathered that pastoral theology is meant to be both accessible and practical. This observation remains true in his more recent work, for readers need not be intimately familiar with Carlin's literary and artistic references to appreciate the way Pastoral Aesthetics models his method.

In the book's conclusion, Carlin imagines his method of correlation applied to nonWestern theological traditions, such as Hinduism or Buddhism, and to philosophical traditions, such as existentialism (Carlin, 2019, p. 146). Thus, this book forum's articles on Pastoral Aesthetics are written in this open-minded spirit of collective investigation; we invited an interdisciplinary group of scholars trained in pastoral theology, bioethics, and the history of medicine to explore Carlin's method in relation to their own work.

Each contributor found Carlin's approach applicable to different aspects of their chosen vocation, and the articles encompass the practices of teaching, ministering, activism, chaplaincy, clinical ethics, and historical analysis. In her article "Pedagogies of Possibilities: Liberating Moral Imagination by Practicing Pastoral Aesthetics," Melinda (Mindy) Sharp (2021), an Associate Professor of Practical Theology and Pastoral Care who is trained in both principlist bioethics and pastoral theology, applies Carlin's method to her work in the classroom. In a final examination in an interdisciplinary course on pastoral theology and care, Sharp asks students to consider the case study of Lisa, a 26-year-old woman dying from cancer, and her physician, Dr. Rayson, a new oncology fellow who is unsure how to respond to Lisa's questions about end-of-life care. At the end of a difficult conversation, Lisa asks whether she should begin to prepare her young children for her death. Should she write a letter to her children now? How much time does she have to wait? Sharp leaves the story open-ended and asks the students to imagine their responses to Lisa's queries. The exercise is designed to engage students' moral imagination and asks them to consider how they might respond, not as "armchair psychologists" but as pastoral theologians who are able to be fully present in the moment. Although this is a challenging skill to teach and to test, Sharp's analysis wholeheartedly agrees with Carlin's methodological proposition: "pastoral aesthetics can help."

In "Systems and Psyches: A Pastoral Perspective on Pastoral Aesthetics," Coble (2021), a minister and scholar of the history of chaplaincy, offers a reflection on his efforts to help his large, politically progressive, majority-white congregation in Asheville, North Carolina, grapple with the legacies of slavery and racism. Coble's congregants have embraced sociocultural explanations of racism and have been supporters of structural solutions, including monetary reparations for the city's Black residents, the removal of Confederate monuments, and the work of an interfaith coalition led by and for "black and brown bodied people." Yet Coble notices racial anxiety among his well-intentioned congregants, a reluctance to do the inner work of exploring exactly how racist structures may have imprinted on their individual psychologies. "If white communities truly want to work for justice, we must do the hard work of going deep inside and excavating the often-unconscious internalizations of white supremacy that we have inherited," writes Coble. Coble argues that the pastoral images of the living human document and the interconnected web should be combined in the practice of ministry rather than understood in isolation. "From a pastoral theological perspective, intertwined images of the web (focusing on oppressive social structure) and the document (the complexities of the human psyche) can guide us in this work. This is the only way that majority-white communities such as my own can begin to live into the principle of justice."

Laws's reflective commentary, "Bioethics_-"Do We Want to Be Made Well?" (2021), similarly addresses issues of justice in principlist bioethics. Laws situates her scholarship 
as a critique of bioethics rooted in African American religious studies and as part of a body of work that seeks to explain the relevance of bioethical issues to Black communities. Laws views Carlin's method as compatible with this perspective because "religion (including theology) is culturally specific"; Carlin's method thus offers one way that African American religious culture might inform principlist bioethics. Laws's commentary imagines Carlin's method in relation to prominent figures in Black Christianity beginning with Martin Luther King Jr. She goes on to discuss how her experiences with racism as a clinical ethics fellow elicit concerns about the misapplication of Carlin's method, particularly the possibility that the method will ultimately "cause more harm than good and will raise awareness but not lead to action." She urges practitioners who adopt Carlin's method to do so alongside a "long-term, prospective commitment" to racial justice and to communities affected by health disparities. "Using Carlin's method will not be for the faint of heart," Laws concludes.

In "Pastoral Aesthetics for Pediatric Bioethics," Bratt Carle (2021), a chaplain in a pediatrics hospital, witnesses children's responses to heartbreaking clinical scenarios and argues that both clinical ethicists and theologians misperceive children as lacking the moral autonomy that belongs to capacitated adults. This view leads to a tendency to conflate autonomy with subjectivity and to see children as "recipients and objects of protection and care" rather than as agents or actors in their own right. Bratt Carle demonstrates how integrating childhood studies into Carlin's interdisciplinary method can help others recognize the emotional, psychological, and spiritual complexity—even maturity - that pediatric patients display throughout clinical ethics dilemmas. "Going forward, bioethical discourse must engage the complex realities of children and childhood and refrain from settling for simplistic renderings of children that measure them and their capacities only in relation to the adults we hope they will one day become," writes Bratt Carle. "Carlin's pastoral aesthetic lays important groundwork for carrying out these efforts."

Clinical ethicist Fanning's "Respecting Autonomy through Reciprocal Recognition and Interlocking Brokenness" (2021) uses Carlin's method to explore the role of agency in the case of Mr. Johnson, a patient who has been hospitalized with a history of "HIV/AIDS, end-stage renal disease on hemodialysis, homelessness, polysubstance use disorder, and bipolar affective disorder with prolonged hospitalization due to pneumonia, profound psychosis, newly diagnosed congestive heart failure." In addition to the diagnoses listed in his medical record, Fanning describes Johnson as a survivor of multiple traumas, including "physical abuse as a child, anti-Black racism, stigmatization associated with HIV/AIDS, psychiatric disease including substance use disorder, incarceration." During repeated hospital stays, Mr. Johnson's stated will to live and his willingness to follow his treatment plan are in conflict. His rage and despair about his endof-life situation finds expression in behavioral conflicts with the medical team as well as his deep spiritual commitment to live for the sake of his family, with whom his relations are continually strained. Fanning draws on theologian Larry Graham's "concept of the interlocking brokenness of selves and worlds in relation to the case and the concept of reciprocal recognition" and, using Carlin's method, correlates this concept with the image of an armored knight in an Albrecht Dürer engraving. Reciprocal recognition is a form of autonomy that acknowledges the cumulative harm of structural injustices on the bodies and psyches of individual patients and offers the possibility of partial reconciliation between patients, families, and the care team in situations where patients are seemingly impervious to accepting love and care. Using Carlin's method, Fanning presents reciprocal recognition as a form of autonomy that is created in relationship with others and attuned to the embodied effects of injustice. 
Finally, Hirshbein (2021), a psychiatrist and historian of medicine, discusses intersections between the histories of psychiatry and clinical pastoral education in order to demonstrate the contingency of therapeutic and historical frameworks for individual suffering and collective crisis. She concludes:

So, in some ways we have come full circle, back to the conditions that led to the stories we have about the origins of both bioethics and pastoral counseling. In the early 20th century, Americans were faced with the stresses of two world wars and a global pandemic. Neither the increasing technology and detachment of medicine nor the preaching of the clergy seemed to be enough to remind people about the essence of humanity. Psychoanalysis filled the gap at that time. Now we have another time of crisis, with profound failures of connection between physicians, systems, and individuals. As Carlin pointed out, the principles of bioethics do not do an adequate job of locating the humanity needed to manage these crises, even within the limited worlds of medical care and research. Bioethics principles have certainly not solved the growing problems as amplified during 2020, at a time of enormous social, cultural, political, and economic upheavals as well as a global pandemic.

Does this mean that the conditions are right for a new revolution, for a radical paradigm shift away from principlist bioethics? Maybe not. Nathan Carlin's Pastoral Aesthetics offers a generative interpretation of the last revolution and a convincing revival of the spiritual dimensions of bioethics in education, pastoral care, activism, scholarship, and clinical practice.

\section{References}

Bauby, J. D. (1998). The diving bell and the butterfly. Vintage.

Beauchamp, T., \& Childress, J. (1979). Principles of biomedical ethics. 1st ed. Oxford University Press. Bratt Carle, J. (2021). Pastoral aesthetics for pediatric bioethics. Pastoral Psychology, 70(6).

Carlin, N. (2019). Pastoral aesthetics: A theological perspective on principlist bioethics. Oxford University Press.

Carlin, N. (2014). Religious mourning: Reversals and restorations in psychological portraits of religious leaders. Wipf and Stock.

Coble, R. (2021). Systems and psyches: A pastoral perspective on Nathan Carlin's Pastoral Aesthetics. Pastoral Psychology, 70(6).

Dykstra, R. (1990). Intimate strangers: The role of the hospital chaplain in situations of sudden traumatic loss. The Journal of Pastoral Care, 44(2), 139-152.

Dykstra, R. (Ed.). (2005). Images of pastoral care: Classic readings. Chalice.

Fanning, J. (2021). Respecting autonomy through reciprocal recognition and interlocking brokenness. Pastoral Psychology, 70(6).

Fink, S. (2013). Five days at memorial: Life and death in a storm-ravaged hospital. Broadway.

Hirshbein, L. (2021). A consideration of Pastoral Aesthetics from the perspective of history. Pastoral Psychology, 70(6).

Laws, T. (2021). Carlin's Pastoral Aesthetics: Bioethics-Do we want to be made well? Pastoral Psychology, 70(6).

Micheli, J. (2016) Cancer is funny: Keeping faith in stage-serious chemo. Fortress.

Ness, P. (2013). A monster calls. Candlewick.

Rothman, D. (1991). Strangers at the bedside: A history of how law and bioethics transformed medical decision making. Basic Books.

Sharp, M. A. M. (2021). Pedagogies of possibilities: Liberating moral imagination by practicing pastoral aesthetics. Pastoral Psychology, 70(6).

Publisher's Note Springer Nature remains neutral with regard to jurisdictional claims in published maps and institutional affiliations. 